\title{
Oral health care practice of women with pregnancy experience
}

\author{
Anne Agustina Suwargiani ${ }^{1,2^{*}}$, Erry Mochamad Arief ${ }^{3}$, Dudi Aripin ${ }^{4}$, Sunardhi \\ Widyaputra $^{5}$, Sri Susilawati \\ 'Doctoral Study Programme, Faculty of Medicine Universitas Padjadjaran, Indonesia \\ ${ }^{2}$ Department of Dental Public Health, Faculty of Dentistry Universitas Padjadjaran, Indonesia \\ ${ }^{3}$ Department of Periodontology, School of Dental Sciences Universiti Sains Malaysia, Malaysia \\ ${ }^{4}$ Department of Conservative Dentistry, Faculty of Dentistry Universitas Padjadjaran, Indonesia \\ ${ }^{5}$ Department of Oral Biology, Faculty of Dentistry Universitas Padjadjaran, Indonesia
}

\begin{abstract}
Introduction: Oral health of pregnant women is essential due to the physiological, psychological, and immune response changes. Oral health-related prenatal services, however, are still insufficient. There are some deficiencies in health care and health promotion activities provided for pregnant women. The purpose of this study was to determine the oral health care practice of women with pregnancy experience. Methods: A cross-sectional descriptive study was conducted towards Indonesian women with pregnancy experience-sample size calculation was conducted using the survey population to estimate the population proportion formula. Inclusion criteria were women with pregnancy experience, owns mobile phones, able to access the Google ${ }^{\circ}$ Form questionnaire, and willing to take part in the study. Exclusion criteria were women with pregnancy experience who did not complete the Google $₫$ Form questionnaire and women who were having a miscarriage or stillborn. Sampling technique was performed using the non-probability sampling with consecutive sampling technique in August until September 2019. Data collection using questionnaire in form of Google ${ }^{\circ}$ Form questionnaire and distributed online to women who has pregnancy experience throughout Indonesia. Results: The respondents were grouped in three age categories: 22-34 years, 35-44 years, and 45-65 years. Respondents came from 45 cities throughout Indonesia. $62.70 \%$ of pregnant women had never visited the dentist. Pregnant women who have visited the dentist were only $37.30 \%$. Pregnant women visited the dentist because they experience a toothache, while the reason for most pregnant women did not visit the dentist because they dd not have any oral health complaints. Conclusion: $62.70 \%$ of pregnant women had never visited the dentist. Pregnant women who have visited the dentist were only $37.30 \%$. Women with pregnancy experience mostly have oral health care to treat their oral health complaints. However, the majority of them never visits the dentist because they did not have any oral health complaints.
\end{abstract}

Keywords: Oral health care, practice, women, pregnancy experience.

p-ISSN: 1979-0201; e-ISSN: 2549-6212; Available from: http://jurnal.unpad.ac.id/pid/article/view/30312

DOI: 10.24198/pjd.vol32no3.30312

Submission: Sep 02, 2020; Accepted: Nov 25, 2020; Published online: Nov 30, 2020

"Corresponding author: Anne Agustina Suwargiani, Doctoral Study Programme, Faculty of Medicine Universitas Padjadjaran, Indonesia. 38, Jalan Professor Eyckman, Bandung, West Java, 40161, Indonesia. Phone: +6281320171707; Email: anne. agustina@fkg.unpad.ac.id 


\section{INTRODUCTION}

Pregnancy is a normal process that results in a series of physiological and psychological changes. This experience is unique and powerful for every woman. However, a normal pregnancy can be accompanied by several problems and complications that potentially threaten the life of maternal and fetal health. ${ }^{1}$ It was found that about $88-98 \%$ of all maternal deaths can be avoided by proper treatment during pregnancy and childbirth. ${ }^{1}$ The antenatal period (ANP) is the most crucial time for pregnant women. Many treatments carried out during ANP improve the welfare of mothers and/or babies and reduce the burden of adverse perinatal outcomes. ${ }^{1}$ WHO has developed specific guidelines regarding the period and content of ANP visits. ${ }^{1}$

Many Asian women continue to performing traditional beliefs and practices during pregnancy. childbirth. ${ }^{2}$ Utilisation of antenatal services is still low among some Asian populations. For example, the United Nations (UN) estimates that only $42 \%$ of women in South Asia receive four or more recommended antenatal care visits. and only $49 \%$ deliver with trained birth attendants. ${ }^{3}$ Coverage of prenatal services (four or more visits) in Laos was only $37 \%$, while it was higher counted in Cambodia and Indonesia, which were $72 \%$ and $84 \%$ respectively. The birth rate with trained personnel is another example of inadequate care, reaching $42 \%$ in Laos, $92 \%$ in Cambodia, $87 \%$ in Indonesia, and $73 \%$ in the Philippines. ${ }^{2}$

The use of formal maternal health services also varies significantly in different countries. Previous research has documented substantial differences in the use of maternal health services among women living in the region of Asia and shows that the lowest level of maternal health services utilisation is often found in the most marginalised groups, such as urban ethnicity. women living in rural areas, women with low formal education. and women with low economic status. ${ }^{2}$

Other indicators of maternal health have shown that there are some deficiencies in health care and health promotion activities provided for pregnant women. ${ }^{4}$ Health promotion and healthy lifestyle must become an integral part of health services provided for pregnant women. Further research is needed to develop instruments that integrate cultural beliefs related to lifestyle practices. $^{4}$

Indonesia has a high level of antenatal services in the health sector. However, oral healthrelated prenatal services are still insufficient. Thus it is necessary to understand the pattern of actions regarding the utilisation of oral health-related antenatal services as a basis for planning the oral health promotion for pregnant women. This study was aimed to determine oral health care practice of women with pregnancy experience.

\section{METHODS}

This research was a cross-sectional study. Crosssectional research design is a type of observational design. In a cross-sectional study, researchers measured the results and exposure towards the study participants at the same time. ${ }^{5}$ The population was women in Indonesia with pregnancy experience. Inclusion criteria were women with pregnancy experience, had mobile phones, able to access the Google ${ }^{\circledR}$ Form questionnaire, and willing to take part in the study. Exclusion criteria were women with pregnancy experience who did not complete the Google ${ }^{\circledast}$ Form questionnaire and women who were having a miscarriage or stillborn.

The study population was Indonesian women with pregnancy experience. Sampling technique was performed using the non-probability sampling with consecutive sampling technique in August until September 2019.

Data collection using questionnaire in form of Google $\circledast$ Form questionnaire and distributed online to women who has pregnancy experience throughout Indonesia. This questionnaire has been internally validated by the Public Health, Oral Biology, and Conservative Dentistry experts. With questions related to oral health practices during pregnancy concerning the dental examination of women with pregnancy experience. The subvariables were the reason for having and not having a dental examination, and experience of dental examination during pregnancy. The questionnaire was divided into two sections, the first section contains five open questions, and the second section contains seven closed questions.

The sample size calculation was conducted using the population survey to estimate the population proportion, with the formula as follows: 
$\mathrm{n}=\mathrm{p}(1-\mathrm{p}) /\left(\mathrm{z}_{1-\mathrm{a}} / \mathrm{d}\right)^{2}$. The $\mathrm{p}$-value as as estimated population proportion for good oral health care practice for women with pregnancy experience was not known, thus, the $p$-value taken was (1-p) for the maximum, which was $0.25(p=0.5)$ to get the maximum sample.

The confidence interval was determined as $95 \%\left(Z_{\text {a-a- }}=1.96\right)$ and the d-value was determined by the research in $6 \%$. Result formulation sample was $0.25(1.96 / 0.05)^{2}$, thus the minimum sample size known as 267 sample. Sample in this study was 346 pregnant women from 45 cities in Indonesia.

Sample size of 346 was more than maximum calculated sample (267 sample), which indicated the good response rate good. The study was conducted concerning the ethical guidelines for research and health development, and all respondents had received informed consent. The ethical clearance approval number from research ethic committee of Universitas Padjadjaran was 1049/UN6.KEP/EC/2020. Data were analysed using Microsoft ${ }^{\oplus}$ Excel, and the relative frequency distribution of the oral health care practice results will presented in tabulation.

\section{RESULTS}

The study results of the oral health care practice of women with pregnancy experience were presented as follows:

Table 1. Age of respondents with pregnancy experience $(n=346)$

\begin{tabular}{ccc}
\hline Age of respondents & $F$ & $\%$ \\
\hline $22-34$ years & 156 & 45.24 \\
$35-44$ years & 144 & 41.50 \\
$45-63$ years & 46 & 13.26 \\
& 346 & 100.00 \\
\hline
\end{tabular}

Table 1 shows that the majority of respondents were at the age of 22-34 years, followed by 35-44 years, and there was the 63 years-old respondent who willingly filled out the questionnaire.Respondents came from 45 cities throughout Indonesia, among them were Tangerang, Bogor, Garut City, Garut Regency, Batujajar, Bandung Clty, Bandung Regency, Indramayu, Karawang, Tasikmalaya, Bekasi City,
Bekasi Regency, Jakarta, Riau, Tegal, Serang, Berau, Sumedang, Banjarmasin, Kendari, Bandar Lampung, Batam, Blora, Depok, Palembang, Semarang, Samarinda, Kerinci, and Magetan.

Table 2 shows that as many as $62.7 \%$ never visited the dentist during their pregnancy. This percentage indicated that pregnant women who never had dental examination was higher women who had dental examination during pregnancy.

Table 2. Dental examination of women with pregnancy experience $(n=346)$

\begin{tabular}{ccc}
\hline Dental examination experience & $\mathrm{F}$ & $\%$ \\
\hline Not having dental examination experience & 217 & 62.70 \\
Having dental examination experience & 129 & 37.30 \\
\hline
\end{tabular}

The reasons for not having dental examination during pregnancy are presented in Table 3 and the reasons for having dental examination during pregnancy are listed in Table 4.

Table 3 shows that the most reasons for not having dental examination during pregnancy was because there are no complaints. Other reasons included already having control visit before pregnancy, feels unnecessary, not having time to see the dentist, fear of affecting the fetus, the teeth not felt badly hurt, pregnancy sickness, there are complaints but afraid to see the dentist, fear of the dentist, not having knowledge regarding the necessary of dental examination, feeling indolent, dentist is rarely found in the rural area, fear of being given drugs, did not receive information, understand the importance 
of going to the dentist but unwillingly have a visit, choose to consult to the dentist informally, misperceptions about dentists, unthinkable, and not having enough money to pay for the dentist.

Table 3. Reasons for not having and having dental examination during pregnancy $(n=217)$

\begin{tabular}{lcc}
\hline Reasons for not having dental examination during pregnancy & F & $\%$ \\
\hline Already having control visit before pregnancy & 2 & 0.92 \\
Not having any complaint & 157 & 72.35 \\
Feels unnecessary & 13 & 5.99 \\
Not having time to see the dentist & 8 & 3.69 \\
Fear of affecting the fetus & 5 & 2.30 \\
The teeth not felt badly hurt & 2 & 0.92 \\
Pregnancy sickness & 1 & 0.46 \\
There are complaints. but afraid to see the dentist & 1 & 0.46 \\
Fear of the dentist & 2 & 0.92 \\
Not having knowledge regarding the necessary of dental examination & 10 & 4.61 \\
Feeling indolent & 2 & 0.92 \\
Dentist is rarely found in the village & 2 & 0.92 \\
Fear of being given drugs & 2 & 0.92 \\
No information & 1 & 0.46 \\
Know the importance of going to the dentist but unwillingly have a visit & 2 & 0.92 \\
Choose to consult to the dentist informally & 1 & 0.46 \\
Misperceptions & 1 & 1.84 \\
Unthinkable & 217 & 0.46
\end{tabular}

Table 4 suggested that 129 respondents have their particular reasons for having dental examination during pregnancy.

Most reason was experiencing toothache, followed with tooth decay, scaling, root planning, and routine examination, and some complaints need to be addressed by a dentist. Other reason were tooth loss, suggested by their obstetrician, laboratory test requirement, general check up, and have a family dentist.

Table 4. Reasons for having dental examination during pregnancy $(n=129)$

\begin{tabular}{lcc}
\hline Reasons for having dental examination during pregnancy & F & $\%$ \\
\hline Experiencing toothache & 35 & 27.13 \\
Experiencing tooth decay & 28 & 21.71 \\
Braces control visit & 8 & 6.20 \\
Suggested by an obstetrician & 1 & 0.78 \\
Scaling and root planning & 18 & 13.95 \\
Routine examination & 18 & 13.95 \\
Some complaints need to be addressed by a dentist & 6 & 4.65 \\
Having tooth extraction & 4 & 3.10 \\
Need information from a dentist & 3 & 2.33 \\
Loose tooth & 1 & 0.78 \\
Effects of pregnancy hormones on oral health & 1 & 0.78 \\
Laboratory test & 1 & 0.78 \\
General check-up & 4 & 3.10 \\
Have dentist's family & 1 & 1 \\
\hline Total & 129 & 100.00 \\
\hline
\end{tabular}


Table 5. Experience of dental examination during pregnancy $(n=129)$

\begin{tabular}{|c|c|c|}
\hline Item experience of dental examination during pregnancy & $\mathbf{F}$ & $\%$ \\
\hline \multicolumn{3}{|l|}{ Referral of pregnant women } \\
\hline No referral. purely of owns will & 108 & 83.72 \\
\hline Referral from obstretrician & 13 & 10.08 \\
\hline Referral from midwives & 6 & 4.65 \\
\hline Direction from family & 2 & 1.55 \\
\hline \multicolumn{3}{|l|}{ Dental examination frequency during pregnancy } \\
\hline 1-time & 67 & 51.90 \\
\hline 2-times & 35 & 27.10 \\
\hline 3-times & 26 & 20.20 \\
\hline Never & 1 & 0.80 \\
\hline \multicolumn{3}{|l|}{ in what pregnancy visit the dentist } \\
\hline 1 & 61 & 47.30 \\
\hline 2 & 33 & 25.60 \\
\hline 3 & 19 & 14.70 \\
\hline Other & 16 & 12.40 \\
\hline \multicolumn{3}{|l|}{ Types of dental health facilities visited ge the dental care } \\
\hline Community health care & 33 & 25.58 \\
\hline Private clinic & 29 & 22.48 \\
\hline Hospital & 27 & 20.93 \\
\hline Private dental practitioner & 40 & 31.01 \\
\hline \multicolumn{3}{|l|}{ Expectations of obtained dental care } \\
\hline Consultation & 54 & 41.86 \\
\hline Tooth filling & 35 & 27.13 \\
\hline Tooth extraction & 13 & 10.08 \\
\hline Others & 27 & 20.93 \\
\hline \multicolumn{3}{|l|}{ The secure feeling when performing dental care } \\
\hline Yes. secure & 114 & 88.37 \\
\hline Slightly & 14 & 10.85 \\
\hline No & 1 & 0.78 \\
\hline \multicolumn{3}{|l|}{ Expectations from a visit to the dentist } \\
\hline Want to feel comfortable with no toothache & 85 & 65.89 \\
\hline Want to feel comfortable with no tooth cavity & 14 & 10.85 \\
\hline Want to feel satisfied with the tooth appearance & 1 & 0.78 \\
\hline Could eat of all types of food & 4 & 3.10 \\
\hline Others & 25 & 19.38 \\
\hline
\end{tabular}

Table 5 shows that the majority (83.7\%) of women with pregnancy experience visited the dentist purely because of their own's will. From 129 respondents who had dental examination, only $12.3 \%$ got referrals from obstetricians, midwives, and families. $51.9 \%$ of pregnant women come to the dentist only once, $27.1 \%$ twice, $20.2 \%$ thrice, and $0.8 \%$ never visited the dentist during their pregnancy. $47.3 \%$ of pregnant women visited the dentist in their first pregnancy, $25.6 \%$ in the 
second pregnancy, $14.7 \%$ in the third pregnancy, and $12.4 \%$ in all pregnancies. Most visited health facilities during pregnancy was a private dental practitioner, followed by community health centre, private clinics, and the least visited was dental hospitals.

Table 5 also showed that during pregnancy, the majority of respondents $(41.86 \%$ ) wanted dental treatment in the form of consultation, followed with a tooth filling in $27.13 \%$ of respondents, tooth extraction in $10.08 \%$ of respondents, and another $20.93 \%$ wanted dental care in the form of scaling and orthodontic treatment. $88.37 \%$ of pregnant women who did dental treatment felt safe, $10.85 \%$ of pregnant women felt slightly insecure, and as many as $0.78 \%$ did not feel safe doing dental care during pregnancy. As much as $65.89 \%$ respondents' expectation of visiting a dentist during pregnancy was to feel comfortable with no toothache, $10.85 \%$ of respondents wanted to feel comfortable with no cavities, $0.78 \%$ of respondents want to be satisfied with their tooth appearance, $3.10 \%$ of respondents wanted to be able to eat all kinds of food, while $19.38 \%$ has other expectations.

\section{DISCUSSION}

The majority of respondents were at the age of 22-34 years (45.24\%), which was similar to the result from the research conducted by Bamanikar et al. ${ }^{19}$, which suggested that most women with pregnancy experience in their research was in the age group of $21-30$ years (53.8\%). Response rate of this study was very good, because respondents who willingly filled out the questionnaire were found until 63-years respondent.

Sixty-two point seven percent of respondents never consulted a dentist (Table 2). This amount showed that pregnant women who did not have a dental examination was higher than those who had an examination. This result was almost the same as with the research conducted by Moawed et al. ${ }^{6}$ which stated that as many as $65 \%$ of pregnant women did not go to the dentist.

The most reasons for not having dental examination during pregnancy are because there were no complaints (Table 3 ). De Sousa et al. ${ }^{24}$ also stated most pregnant women do not visit a dentist during their pregnancy. Other reasons included already having control visit before pregnancy, feels unnecessary, not having time to see the dentist, fear of affecting the fetus, the teeth not felt badly hurt, pregnancy sickness, there are complaints but afraid to see the dentist, fear of the dentist, not having knowledge regarding the necessary of dental examination, feeling indolent, dentist is rarely found in the rural area, fear of being given drugs, did not receive information, understand the importance of going to the dentist but unwillingly have a visit, choose to consult to the dentist informally, misperceptions about dentists, unthinkable, and not having enough money to pay for the dentist (Table 4).

The reasons stated above, however, were different from the findings of Hartnett et al. ${ }^{7}$ Hartnett suggested that both personal stressors such as financial, employment, and domestic problems, and dental care issues, such as time, cost, attitudes of dental providers, and lack of comprehension on the importance of oral health were some of the barriers that prevented pregnant women from accessing dental care during pregnancy. ${ }^{7}$ The results of the present study indicated that recommendation of oral health programs in prenatal services is essential to the delivery of dental care and decreasing the potential oral problems among pregnant women, as well as conducting a careful initial screening of oral risks, and assisting women in obtaining regular dental care. ${ }^{6}$

As many as $83.72 \%$ of 129 pregnant women go to the dentist purely because of their own's will, while only very few of them get direction from their family (Table 3 ). These results were slightly different from the research conducted by Karasu et al. ${ }^{8}$ which stated that during their pregnancy. 59 of women with pregnancy experience $(12.4 \%)$ had a dental visit during their pregnancy, and 24 of them $(5.1 \%)$ had a professional treatment. This result indicated the critical role of obstetricians and midwives in conveying the importance of dental care to their patients. There is an urgent need to identify dental health care utilization of pregnant women ${ }^{8}$, so that pregnant women are aware of the importance and safety of receiving oral health care during pregnancy. ${ }^{9}$

Only $10.08 \%$ of 129 respondents received guidance from obstetricians, or midwives, or families (Table 5). These results were consistent with the results of the study conducted by Morgan 
et al. ${ }^{10}$ which discovered that $84 \%$ of obstetriciangynecologists were aware of the importance of oral health in pregnancy but that $54 \%$ did not ask about oral health issues, and $69 \%$ did not provide information on oral health. Furthermore, only $62 \%$ recommended dental visits for their patients. ${ }^{7}$ The 2013 Committee Opinion from the American College of Obstetricians and Gynecologists recommends that all health care providers assess oral health at the first prenatal visit. ${ }^{11}$

The perinatal period is the most proper moment to counsel oral health care and can potentially affect maternal and infant health. ${ }^{7}$ The results of this current study indicated that lack of referrals from midwives $4.65 \%$ was different from the results of a study conducted by Wagner et al. ${ }^{12}$ suggested that in general. More than a half of the midwives $(53.5 \%)$ recommended a dental visit during pregnancy. The engagement percentage value above showed that to increase oral awareness and to improve oral health knowledge among midwives and all other healthcare professionals. Uniform guidelines must be developed. ${ }^{12}$

Programs to develop educational resources for pregnant women can be designed, such as developing community resources for dental service providers who are willingly conducting oral health examinations for pregnant women. This program is needed to provide specific strategies to teach future health service providers on how to promote effective self-management for oral and overall health in their patients through interprofessional collaborative practices, health literacy, and community services. The program provides a strong foundation for future collaborative practice, highlighting that dental referral for pregnant women is essential for safer practice. ${ }^{7}$

For as many as $51.90 \%$ of pregnant women come to the dentist only once, $27.10 \%$ twice, $20.20 \%$ thrice, and $0.80 \%$ never visited the dentist during pregnancy (Table 5). These results was following the previous research which discovered that half of the women who reported oral health issues do not seek treatment because they believe poor oral health during pregnancy is normal or they worry that dental care can harm the fetus ${ }^{13}$ and there is more supporting evidence that most pregnant women did not even visit the dentist. The Cigna Corporation conducted a national survey in 2015 of 801 pregnant women, which only half of whom had dental insurance. They found that although $76 \%$ of pregnant women reported that they had a dental problem. only $57 \%$ reported a dental visit during pregnancy. Those with dental insurance were twice as likely to visit the dentist. ${ }^{14}$ Also, many pregnant women do not perceive gingival bleeding as indicating inflammatory disease and seek no professional help for it. Maternity care providers need to devote more attention to oral health in antenatal clinics and antenatal education. ${ }^{15} \mathrm{~A}$ woman's lack of receiving routine dental care when not pregnant was the most significant predictor of lack of receiving dental care during pregnancy. ${ }^{16}$

Pregnancy is a unique period with various physiologic changes that support the formation and maturation of a new life. Every gestational woman should be encouraged to seek medical and dental care during pregnancy, as a failure in treating the developing problems affects the health of both the mother and the unborn child. ${ }^{17}$ Pregnancy causes many changes in the physiology of the female patient. These alterations are sometimes subtle but can lead to disastrous complications if proper precautions are not taken during dental treatment.

Increased hormonal secretion and fetal growth induce several systemic, as well as local physiologic and physical changes in a pregnant woman. Local physical changes occur in different parts of the body, including the oral cavity. These collective changes may pose various challenges in providing dental care for the pregnant patient. Treatment of the pregnant patient has the potential to affect the lives of two individuals (the mother and the unborn fetus). ${ }^{18}$

Table 5 shows that $47.30 \%$ of pregnant women visited the dentist in their first pregnancy, $25.60 \%$ in the second pregnancy, $14.70 \%$ in the third pregnancy, and $12.40 \%$ in all pregnancies. Dental treatment during pregnancy needs to be carried out in the first, second, and subsequent pregnancies. These results were almost similar to the previous studies, which discovered that although the majority of pregnant women attending the MCH Clinic, Jubli Perak Sengkurong Health Centre, Brunei Darussalam (96.8\%) agreed that women should have a dental check-up during pregnancy, only $55.9 \%$ practiced this. This 
condition raises serious concern since pregnant women may need extraoral and dental care due to susceptibility to gum diseases during pregnancy. which may contribute to low birth weight babies and premature births. ${ }^{19}$

The storm of hormones which is induced during pregnancy causes changes in the mother's body, and the oral cavity is no exception. ${ }^{17}$ The oral changes which are seen in pregnancy include gingivitis, gingival hyperplasia, pyogenic granuloma, and salivary changes. Increased facial pigmentation is also seen. Elevated levels of the circulating estrogen, which cause an increased capillary permeability, predispose the pregnant women to gingivitis and gingival hyperplasia. Pregnancy gingivitis usually affects the marginal and the interdental papilla and it is related to the preexisting gingivitis. Good oral hygiene can help in preventing or reducing the severity of the hormone-mediated inflammatory oral changes. ${ }^{17}$

Most visited health facilities during pregnancy was a private dental practitioner, which was visited by $31.01 \%$ of 129 pregnant women, followed by community health centre $(25.58 \%)$, private clinics $(22.48 \%)$, and the least visited were hospitals $(20.93 \%)$. These results were consistent with a research conducted by Saddki et al. ${ }^{20}$, which discovered that the majority of the mothers preferred dentists in private practices (58.3\%) compared to the government clinics.

Hancock et al. ${ }^{21}$ also suggested that most mothers visited private dentists for their oral health care during pregnancy. Results from these previous studies. along with the current study result, are possible because most participants were working mothers, or mothers with limited spare time. As time is an important limitation for most of them, visiting a private practitioner may be a more convenient option since private clinics are mostly accessible after hours and during weekends. Waiting time at private clinics is also relatively short. and treatment can be started immediately. ${ }^{20.21}$

Eighty eight point three and seven percent of 129 pregnant women who did dental treatment felt safe, $10.85 \%$ of 129 pregnant women felt slightly insecure, and as many as $0.78 \%$ of 129 pregnant women did not feel safe doing dental care during pregnancy. According to the findings of the study conducted by Strafford et al..$^{22}$, which suggested that $84 \%$ of women felt dental visits were safe during pregnancy, and $54 \%$ indicated that they were more critical than when not pregnant.

A previous study conducted towards pregnant women attending a large hospital in South-Western Sydney, however, discovered that the main barriers to seeking dental care for these women were safety concerns regarding dental treatment during pregnancy. ${ }^{23} \mathrm{~A}$ surprising fact also found in this study, which was consistent with the result of our current research, that $82.2 \%$ of the women who already had dental visits during their pregnancy are fully aware that dental treatment is safe during pregnancy. ${ }^{23}$ It is therefore timely for the private dentists to take a more active role in oral health promotion and services to antenatal mothers.

Majority $(65.89 \%)$ of 129 pregnant women expectation of visiting a dentist during pregnancy was to feel comfortable with no toothache. As many as $10.85 \%$ of them wanted to feel comfortable with no cavities, $0.78 \%$ want to be satisfied with their tooth appearance, and $3.10 \%$ wanted to be able to eat all kinds of food. Most of the pregnant women visit the dentist in expectation of relieving their oral health problem.

Majority of the mothers might be claimed that their oral health status was good or very good, as also found in the present study, which became one of the barriers for them in visiting the dentist. However, most of them admitted of having had at least one oral health problem (59.7\%) including cavitated (43.5\%) and painful teeth (15.3\%), bleeding gum (21.0\%), and bad breath, as also discovered in the study conducted by Saddki et al. ${ }^{20}$ Adequate exposure to oral health education before the pregnancy and awareness of relationship between poor maternal oral health and adverse pregnancy outcomes may have the double effect in fulfilling their expectancies in visiting the dentist, and also improving the better health status for the mother and the fetal.

Limitations in this study was that the sample not cover all cities in every province in Indonesia. This can be happen due to the limitation of the research period and many pregnant women who fill out the Google ${ }^{\circledR}$ Form questionnaire did not want their outcome to be involved in the research. 


\section{CONCLUSION}

$62.70 \%$ of pregnant women had never visited the dentist. Pregnant women who have visited the dentist were only $37.30 \%$. Women with pregnancy experience mostly have oral health care to treat their oral health complaints. However, the majority of them never visits the dentist because they did not have any oral health complaints.

\section{REFERENCES}

1. Ibrahim HK, El Borgy MD, Mohammed HO. Knowledge, attitude, and practices of pregnant women towards antenatal care in primary healthcare centers in Benghazi, Libya. J Egypt Public Health Assoc. 2014; 89(3): 119-26. DOI: 10.1097/01.EPX.0000455673.91730.50

2. Withers M, Kharazmi N, Lim E. Traditional beliefs and practices in pregnancy, childbirth and postpartum: A review of the evidence from Asian countries. Midwifery. 2018;56:15870. DOI: $10.1016 / j . m i d w .2017 .10 .019$

3. Grenier L, Suhowatsky S, Kabue MM, Noguchi LM, Mohan D, Karnad SR, et al. Impact of group antenatal care (G-ANC) versus individual antenatal care (ANC) on quality of care, ANC attendance and facility-based delivery: A pragmatic cluster-randomized controlled trial in Kenya and Nigeria. PLoS One. 2019;14(10):118. DOI: $10.1371 /$ journal.pone. 0222177

4. Gharaibeh M, Al-Maaitah R, Jada NA. Lifestyle practices of Jordanian pregnant women. Int Nurs Rev. 2005;52(2):92-100. DOI: 10.1111/j.1466-7657.2005.00257.x

5. Setia M. Methodology series module 3: Cross-sectional studies. Ind J Dermatol. 2016;61(3):261. DOI: 10.4103/0019$\underline{5154.182410}$

6. Moawed S, Badawy AS, Alosimi S, Alrowily $M$. The oral health knowledge and selfcare practices of pregnant women in Saudi Arabia. Am J Nurs Res. 2019;7(4):643-51. DOI: 10.12691/ajnr-7-4-25

7. Hartnett E, Haber J, Krainovich-Miller B, Bella A, Vasilyeva A, Kessler JL. Oral health in pregnancy. J Obstet Gynecol Neonatal Nurs. 2016;45(4):565-73. DOI: $10.1016 / \mathrm{j}$. jogn.2016.04.005

8. Karasu AFG, Kutuk N, Aydin S, Adanir I, Ates
S, Bademler N. Dental health dispositions of pregnant women: Asurvey from a hospital clinic in Istanbul. J Obstet Gynaecol. 2017;37(6):7526. DOI: $10.1080 / 01443615.2017 .1306837$

9. George A, Johnson M, Blinkhorn A, Ellis S, Bhole S, Ajwani S. Promoting oral health during pregnancy: current evidence and implications for Australian midwives. J Clin Nurs. 2010;19(23-24):3324-33. DOI: 10.1111/j.1365-2702.2010.03426.x

10. Morgan MA, Crall J, Goldenberg RL, Schulkin J. Oral health during pregnancy. J Matern Fetal Neonatal Med. 2009;22(9):733-9. DOI: 10.3109/14767050902926954

11. American Academy on Pediatric Dentistry, American Academy of Pediatrics. Policy on early childhood caries (ECC): classifications, consequences, and preventive strategies. Pediatr Dent. 2008-2009;30(7 Suppl):40-3.

12. Wagner $\mathrm{Y}$, Heinrich-Weltzien R. Midwives' oral health recommendations for pregnant women, infants and young children: results of a nationwide survey in Germany. BMC Oral Health. 2016;16(1). DOI: 10.1186/s12903-0160192-1.

13. Luc E, Coulibaly N, Demoersman J, Boutigny $H$, Soueidan A. [Dental care during pregnancy]. Schweiz Monatsschr Zahnmed. 2012;122(11):1047-63.

14. Cigna Corporation. Healthy smiles for mom and baby: Insights into expecting and new mothers' oral health habits. New York: Cigna Corporation; 2015.

15. Keirse MJ, Plutzer K. Womens attitudes to and perceptions of oral health and dental care during pregnancy. J Perinatal Med. 2010;38(1). DOI: $10.1515 / j p m .2010 .007$

16. Boggess KA, Urlaub DM, Massey KE, Moos M-K, Matheson MB, Lorenz C. Oral hygiene practices and dental service utilization among pregnant women. J Am Dent Assoc. 2010;141(5):553-61. DOI: $10.14219 /$ jada.archive.2010.0228

17. Hemalatha VT, Manigandan T, Sarumathi T, Aarthi Nisha V, Amudhan A. Dental considerations in pregnancy-Acritical review on the oral care. J Clin Diagn Res. 2013;7(5):94853. DOI: $10.7860 / j \mathrm{cdr} / 2013 / 5405.2986$

18. Kurien $S$, Kattimani VS, Sriram RR, Sriram SK, Rao VKP, Bhupathi A, et al. Management of pregnant patient in dentistry. J Int Oral 
Health. 2013;5(1):88-97.

19. Bamanikar S, Kee LK. Knowledge, attitude and practice of oral and dental healthcare in pregnant women. Oman Medical Journal. 2013;28(4):288-91. DOI: $10.5001 /$ omj.2013.80

20. Saddki N, Yusoff A, Hwang YL. Factors associated with dental visit and barriers to utilisation of oral health care services in a sample of antenatal mothers in Hospital Universiti Sains Malaysia. BMC Public Health. 2010;10(1). DOI: 10.1186/1471-2458-10-75

21. Hancock M, Calnan M, Manley G. Private or NHS general dental service care in the United Kingdom? A study of public perceptions and experiences. J Public Health. 1999;21(4):41520. DOI: $10.1093 / \mathrm{pubmed} / 21.4 .415$
22. Strafford KE, Shellhaas C, Hade EM. Provider and patient perceptions about dental care during pregnancy. J Matern Fetal Neonat Med. 2008;21(1):63-71. DOI: 10.1080/14767050701796681

23. George A, Johnson M, Blinkhorn A, Ajwani $S$, Bhole $S$, Yeo A, et al. The oral health status, practices and knowledge of pregnant women in south-western Sydney. Aust Dent J. 2013;58(1):26-33. DOI: $10.1111 /$ adj.12024

24. de Sousa LLA, Cagnani A, de Souza Barros AM, Zanin L, Florio FM. Pregnant women's oral health: Knowledge, practices and their relationship with periodontal disease. Rev Gauch Odontol. 2016; 64(2): 154-63. DOI: 10.1590/1981-863720160002000053036 